\title{
Bidirectional associations between activity- related parenting practices, and child physical activity, sedentary screen-based behavior and body mass index: $a$ longitudinal analysis
}

\author{
Ester F. C. Sleddens ${ }^{1}$, Jessica S. Gubbels ${ }^{1 *}$, Stef P. J. Kremers ${ }^{1}$, Eline van der Plas ${ }^{1}$ and Carel Thijs ${ }^{2}$
}

\begin{abstract}
Background: It has been generally assumed that activity-related parenting practices influence children's activity behavior and weight status. However, vice versa parents may also change their parenting behaviors in response to their perceptions of their child's activity behavior and weight status. This study examined the bidirectional relationships between activity-related parenting practices, and physical activity, sedentary screen-based behavior, and body mass index (BMI) between children's age of 5 and 7 years.

Methods: Three scales of the Activity-related Parenting Questionnaire (i.e. 'restriction of sedentary behavior', 'stimulation of physical activity', and 'monitoring of physical activity') were completed by 1694 parents of the Dutch KOALA Birth Cohort Study at the child's age of around 5 and again around age 7. Physical activity, sedentary screen-based behavior and BMl were measured at both ages as well. Linear regression models were used to estimate the bidirectional associations between each parenting practice and the child's physical activity levels, sedentary screen-based behavior and BMI z-scores.

Results: Several parenting practices at age 5 predicted child physical activity, sedentary screen-based behavior, and BMI z-scores at age 7. Restriction of sedentary behavior positively predicted child BMI and sedentary screen-based behavior, whereas this practice negatively predicted child physical activity. In addition, stimulation of physical activity at age 5 was significantly associated with higher levels of child physical activity at age 7. The following child factors at age 5 predicted parenting practices at age 7: Child physical activity positively predicted parental stimulation of physical activity and monitoring activities. Sedentary screen-based behavior was associated with lower parental stimulation to be active.

Conclusions: Findings generally revealed that parents and children mutually influence each other's behavior. A reinforcing feedback loop was present between parental stimulation of physical activity and child physical activity. Bidirectional parentchild interaction should be considered in future research in order to properly inform parenting-related intervention programs aimed at preventing or treating childhood overweight or obesity. System dynamic methods to explore the existence of reinforcing or balancing loops are needed in this regard.
\end{abstract}

Keywords: Activity-related parenting practices, Bidirectional associations, Body mass index, Children, Physical activity, Sedentary screen-based behavior

\footnotetext{
* Correspondence: jessica.gubbels@maastrichtuniversity.nl

'Department of Health Promotion, NUTRIM School of Nutrition and

Translational Research in Metabolism, Maastricht University, Maastricht

University Medical Center, P.O. Box 616, 6200 MD Maastricht, the Netherlands

Full list of author information is available at the end of the article
}

(c) The Author(s). 2017 Open Access This article is distributed under the terms of the Creative Commons Attribution 4.0 International License (http://creativecommons.org/licenses/by/4.0/), which permits unrestricted use, distribution, and reproduction in any medium, provided you give appropriate credit to the original author(s) and the source, provide a link to the Creative Commons license, and indicate if changes were made. The Creative Commons Public Domain Dedication waiver (http://creativecommons.org/publicdomain/zero/1.0/) applies to the data made available in this article, unless otherwise stated. 


\section{Background}

Parenting practices are content-specific acts of parenting [1], such as rules about activity behaviors. The literature on parenting and childhood obesity is dominated by studies about specific food-related parenting practices [2], whereas physical activity-related parenting practices are less studied but gaining interest during the last few years. Xu, Wen \& Rissel [3] conducted a review about associations of parental influences with children's physical activity and screen time, and found that parental encouragement and support increase children's physical activity. In addition, reducing parents' own screen time can lead to decreased child screen time. Earlier, two reviews were conducted on the then available activityrelated parenting practices measures and associations with either physical activity or screen time $[4,5]$. They found mixed evidence regarding the association between activity-related parenting practices and child physical activity and screen time [4,5]. Despite limitations in existing studies, findings from a previous systematic review concluded based on their systematic review that supporting physical activity behaviors (including modeling) were positively related to children's physical activity levels [5]. However, previous research hypotheses have been largely unidirectional, assuming that parenting practices induce child behaviors. In addition, most of these studies were cross-sectional in nature and therefore causality could not be assessed [5].

'The chicken or the egg' causality issue has hardly been addressed in the study of parent-child interactions in the development of childhood obesity. A few researchers tried to disentangle this issue in the parental feeding domain (e.g., [6-9]) (although solely with child BMI as a predictor and outcome and not dietary behavior), but studies that address microsystem dynamics with regard to activity-related parenting are lacking to date. The studies of parent-child interaction in the feeding domain found that food parenting practices were often influenced by the child's weight status, in addition to the food parenting practice influencing the child's weight gain [7-9]. Despite these findings, the energy balance-related parenting literature is dominated by studies characterizing parents as the agents acting upon the child, without considering children's influence on parents $[10,11]$.

The aim of this study was to examine bidirectional associations between activity-related parenting practices (i.e., restriction of sedentary behavior, stimulation of physical activity, and monitoring of child physical activity), child physical activity and sedentary screen-based behavior, and parental perception of child weight status at age 5 and age 7 . Based on previous food-parenting studies, we hypothesized parenting practices to be a response to child activity behavior and Body Mass Index (BMI), in addition to being a cause. The longitudinal design made it possible to examine the bidirectional nature of the parent-child dynamics: whether activity-related parenting practices predicted change in child activity behavior and BMI; or whether child activity behavior and BMI predicted change in activity-related parenting practices.

\section{Methods}

\section{Data collection and participants}

Data were collected within the KOALA Birth Cohort Study in the Netherlands (described elsewhere) [12]. Briefly, from 2000 onwards, healthy pregnant women from the general population who participated in an existing cohort study on pregnancy-related pelvic girdle pain were recruited ( $N=2343$; referred to as the 'conventional' recruitment group). In addition, healthy pregnant women with an 'alternative' lifestyle with regard to dietary habits (e.g., preferring organic foods), vaccination programs and/or antibiotics use $(N=491$; referred to as the 'alternative' recruitment group) were recruited through several 'alternative' circles like anthroposophical physician offices and midwives, and organic food shops. All participants $(N=2834)$ were enrolled between 14 and 18 weeks of gestation and completed questionnaires during pregnancy and at regular intervals after birth. Informed consent was signed by all parents, and ethical approval was obtained from the Maastricht University/University Hospital Maastricht medical ethics committee.

For the current study we used data from the measurements around the child's age of 5 and again around age 7. In total, 2061 participants ( $72.7 \%$ of the initial cohort) completed the questionnaire around age 5 and 1810 participants $(63.9 \%$ of the initial cohort) completed the questionnaire around the child's age of 7. Of those, 1694 completed the child's parent-reported physical activity behavior questions and/or the activity-related parenting practices at both measurements. Children that were included in the final analyses had a somewhat higher BMI z-score at age 7 compared to children not included $(-0.32$ vs. $-0.53, p$-value $=0.03)$. There was no other selective drop-out (all $p$-values $>0.05$ ) with regard to recruitment group or other child or parental background characteristics. Child mean $(S D)$ age during the first measurement around age 5 was $5.00(0.53)$ years (range 3 to 6 years), and during the second measurement around age 7 was $7.17(0.65)$ years (range 5 to 8 years).

\section{Measures}

At both measurements similar questions were asked regarding activity-related parenting practices, child physical activity behavior and child weight and height.

\section{Activity-related parenting practices}

We used the Activity-related Parenting Questionnaire [13], which was based on the Child Feeding Questionnaire 
[14] and adapted to assess physical activity and sedentary screen-based behavior parenting practices. Three scales from this questionnaire were used for the current study: 'restriction of sedentary behavior' (assessing the extent to which parents restrict their child's access to sedentary activities; 7 items), 'stimulation to be physically active (assessing the extent to which parents encourage their child to be physically active; 3 items)' and 'monitoring activity (assessing the extent to which parents oversee their child's physical activity; 2 items)'. In the current study we decided to delete the item 'As a reward for good behavior, I put on a nice video/DVD/computer game for my child' originally belonging to the scale labeled 'restriction of sedentary behavior'. This item was dropped prior to the analyses based on potential mismatch with this scale. For all three scales, a five-point Likert scale has been used ranging from 1 (Completely disagree) to 5 (Completely agree) for 'restriction of sedentary behavior' and 'stimulation to be active', and ranging from 1 (Never) to 5 (Always) for 'monitoring activity'. The items used to assess these activity-related parenting practices and the corresponding Cronbach's alphas at both measurements are listed in Table 1. Intercorrelations between the different parenting practices were low to moderate, ranging from 0.19 to 0.33 .

\section{Child activity behavior and body mass index}

Children's activity behavior was assessed using questions based on a standard questionnaire for measuring activity behavior, used in Dutch Youth Health Care [15]. Parents were asked on how many days in a normal week during the last 4 weeks their child went to school by bicycle or on foot, had played sports at a sports club, and had played outside (outside school hours). A second question assessed the average duration of each of these activities, with five predefined answering categories ranging from half an hour or less, to $3 \mathrm{~h}$ or more. Based on the assumption that there is a linear association between physical activity and parenting practices [5], we recoded the answer scale to calculate the average time of these activities. Half an hour or less was recoded into $15 \mathrm{~min}$, half an hour to $1 \mathrm{~h}$ into $45 \mathrm{~min}, 1$ to $2 \mathrm{~h}$ into $90 \mathrm{~min}, 2$ to $3 \mathrm{~h}$ into $150 \mathrm{~min}$ and finally, $3 \mathrm{~h}$ or more into $181 \mathrm{~min}$. For the item 'child went to school by bicycle or on foot' answering categories were similar as above for age 7, but different for the measurement at age 5 . The answering categories at age 5 for this item were: shorter than $10 \mathrm{~min}$ (recoded into $5 \mathrm{~min}$ ), $10-20 \mathrm{~min}$ (recoded into $15 \mathrm{~min}$ ), 20-30 min (recoded into $25 \mathrm{~min}$ ), half an hour$1 \mathrm{~h}$ (recoded into 45), and more than $1 \mathrm{~h}$ (recoded into $61 \mathrm{~min}$ ). The duration and number of days were multiplied to calculate the number of minutes spent on a particular activity per week. The number of minutes spent on the various activities were then added up to calculate the total number of minutes of physical activity per week, which was divided by 7 to get the average time (in minutes) the children were physically active per day. Sedentary screen-based behavior was assessed in a similar manner, asking parents about their child's television watching (including videos and DVDs) and computer playing (including game consoles). A similar approach was followed as for physical activity to calculate the number of screen hours per day.

During both measurements, parents were asked to report their child's weight and height (measured without shoes and clothes, specified to one decimal), in order to calculate the child's BMI (weight $(\mathrm{kg}) /\left(\right.$ height $\left.(\mathrm{m})^{2}\right)$. BMI was then recoded into BMI $\mathrm{z}$-scores compared to the 1997 national reference population (i.e., the Fourth Dutch National Growth Study) [16]. BMI z-score $>$ 85th percentile was considered to indicate overweight and a BMI z-score $>95$ th percentile was considered to indicate obesity [17]. Anthropometric scores were systematically checked for plausibility using the following procedure. All outliers ( $\mathrm{z}$-scores $>3$, i.e. more than 3 standard deviations from the mean) for height, weight and BMI were

Table 1 Descriptive and scale information of the activity-related parenting practice scales $(N=1694)$

\begin{tabular}{|c|c|c|}
\hline \multirow[t]{2}{*}{ Activity-related parenting practices } & \multicolumn{2}{|c|}{$\begin{array}{l}\text { Cronbach's alpha; } \\
\text { Mean (SD) }\end{array}$} \\
\hline & $\begin{array}{l}\text { Age } \\
5 \text { years }\end{array}$ & $\begin{array}{l}\text { Age } \\
7 \text { years }\end{array}$ \\
\hline $\begin{array}{l}\text { Restriction of sedentary behavior } \\
\text { - I have to be sure that my child does not... } \\
{ }^{*} \ldots \text { watch too much television. } \\
{ }^{*} \text {... play too many computer games. } \\
\text { - If I did not guide or regulate my child's activity } \\
\text { behavior, (s)he would.. } \\
{ }^{*} \text { watch too much television or play too many } \\
\text { computer games. } \\
{ }^{*} \text { not get enough physical activity. } \\
{ }^{*} \text { be sedentary a lot (or play without being } \\
\text { physically active). } \\
\text { - I intentionally keep my child away from the } \\
\text { television or computer. }\end{array}$ & $\begin{array}{l}0.71 \\
3.00 \\
(0.76)\end{array}$ & $\begin{array}{l}0.72 \\
3.12 \\
(0.75)\end{array}$ \\
\hline $\begin{array}{l}\text { Stimulation to be active } \\
\text { - If my child says "I don't feel like walking or } \\
\text { bicycling to there", I try to get him/her to do } \\
\text { this anyway. } \\
\text { - I have to be careful that my child gets enough } \\
\text { exercise. } \\
\text { - I make sure that my child travels actively on } \\
\text { foot or by bicycle (with or without me) as often } \\
\text { as possible. }\end{array}$ & $\begin{array}{l}0.58 \\
4.26 \\
(0.65)\end{array}$ & $\begin{array}{l}0.56 \\
4.45 \\
(0.53)\end{array}$ \\
\hline $\begin{array}{l}\text { Monitoring activity } \\
\text { How much do you keep track of... } \\
\text {-..the amount of television your child watches } \\
\text { and how many computer games (s)he plays? } \\
\text { - ..the amount of physical activity your child has? }\end{array}$ & $\begin{array}{l}0.64 \\
3.94 \\
(0.79)\end{array}$ & $\begin{array}{l}0.57 \\
4.00 \\
(0.67)\end{array}$ \\
\hline
\end{tabular}

The Corrected-Item Total Correlations for each of the items were above 0.30; The item 'as a reward for good behavior, I put on a nice video/DVD/computer game for my child' originally belonging to the scale labeled 'restriction of sedentary behavior' was already dropped prior to the analyses based on theory; response scale ranging from 1 (Completely disagree) to 5 (Completely agree) for 'restriction of sedentary behavior' and 'stimulation to be active', response scale ranging from 1 (Never) to 5 (Always) for 'monitoring activity 
identified. In addition, longitudinal anthropometric data were checked for inconsistencies and impossible and highly unlikely changes (e.g. a child shrinking in height). The outliers and inconsistencies were then checked with the original paper questionnaires. If the outlier could not be corrected based on this check, it was recoded into a missing value.

\section{Background variables}

As child covariates we included birth weight (in grams) and gender. With regard to parental covariates we included employment (i.e., the number of working hours per week) of the questionnaire completer and partner, their country of birth, and the highest parental educational level attained in the household at the child's age of 5. Educational level was recoded into three levels (low, medium and high), in line with international classification systems [18]. Country of birth was recoded into 'Netherlands' versus 'other'. We additionally included the recruitment group ('conventional' versus 'alternative') as a covariate in all analyses.

\section{Data analyses}

Statistical analyses were performed using the statistical software package IBM Statistics 21. Descriptive statistics were used for the background characteristics of the sample. Both internal reliability coefficients (Cronbach's $\alpha$ ) and Corrected Item-Total Correlations (CITC) were calculated for the scales of the Activity-related Parenting Questionnaire at both ages. A cut-off point of 0.50 for Cronbach's $\alpha$ was used [19]. CITC values above 0.30 were regarded as 'good' [20].

To assess the bidirectional associations between activityrelated parenting practices and the child's physical activity, sedentary screen-based behavior and BMI, two sets of linear regression models were conducted. Each set of models examines one of the two assumed directions of the association. The first set of models (A) examined the association between each of the activity-related parenting practices at age 5 and child's physical activity, sedentary screen-based behavior and BMI z-scores at age 7. The second set (B) examined the associations between the child's physical activity, sedentary screen-based behavior, and BMI at age 5 and each of the parenting practice scales at age 7. For both directions, three models are presented: Model 1: an unadjusted model; Model 2: a model adjusted for covariates (recruitment group; child birth weight and gender; parental employment, country of birth and educational level); and Model 3: a model adjusted for covariates and additionally for either baseline physical activity, sedentary screen-based behavior, or BMI z-score (in the models examining parenting practices as a predictor of child behavior and BMI (A)), or for baseline parenting practices (in the models examining child behavior as a predictor for later parenting practices (B)). Controlling for these baseline scores at age 5 in this third model allows for examination of the effect of changes within the dependent variable between ages 5 and 7 years, independent of the child's baseline scores on the dependent variable.

\section{Results}

\section{Sample characteristics}

The percentage boys and girls taking part in the study were about equally distributed (Table 2). Most families were included in the category with the highest education level achieved (67.8\%). The majority of the questionnaires were completed by mothers (97.6\%). The majority of participants were of Dutch origin (more than 96\% for both female and male caregivers). The children's mean $(S D)$ physical activity in minutes per week was 610.81 (394.25) at age 5 and increased to 904.48 (375.42) at age 7. For sedentary screenbased behavior this was 363.16 (292.19) minutes per week at age 5 and increased to 553.08 (351.69) at age 7. Mean $(S D)$ BMI z-score at age 5 was $-0.26(0.99)$, compared to $-0.32(0.91)$ at age 7 . To specify, $8.9 \%$ of the children were identified as being overweight/obese at age 5 , whereas this decreased to $6.4 \%$ at age 7 .

\section{Associations between activity-related parenting practices at age 5 and child BMI/physical activity/sedentary screen- based behavior at age 7}

For a visual inspection of the significant associations found between activity-related parenting practices at age 5 and child BMI, physical activity and sedentary screen-based behavior development up to age 7 we refer to Fig. 1a. The parenting practice 'restriction of sedentary behavior' showed positive associations with BMI $z$-score and sedentary screen-based behavior at age 7 (Table 3), even after correction for potential confounders and for the child's behavior at age 5 (i.e., for BMI z-score at age 5 when BMI at age 7 was predicted and for child sedentary screen-based behavior at age 5 when sedentary screen-based behavior at age 7 was predicted). In the final model (model 3), the association with sedentary screen-based behavior was marginally significant $(p=0.055)$. Restriction of sedentary behavior was negatively associated with the child's physical activity level at age 7 . Stimulation to be active was only related to the child's physical activity. Higher scores on stimulation to be active were significantly associated with an increase of mean scores of the child's physical activity 2 years later. In addition, parental monitoring of their child's activity was not associated with children's BMI, physical activity levels or sedentary screenbased behavior.

\section{Associations between child BMI/physical activity/ sedentary screen-based behavior at age 5 and activity- related parenting practices at age 7}

For a visual inspection of the significant associations found between physical activity-related variables at age 5 
Table 2 Sample Characteristics $(N=1694)$

\begin{tabular}{|c|c|c|c|c|c|c|c|c|c|}
\hline \multirow{2}{*}{ Description } & & \multirow[b]{2}{*}{$n$} & \multirow[b]{2}{*}{$\%$} & \multicolumn{2}{|c|}{ Age 5 years } & \multirow[b]{2}{*}{ Mean (SD) } & \multicolumn{2}{|c|}{ Age 7 years } & \multirow[b]{2}{*}{ Mean (SD) } \\
\hline & & & & $n$ & $\%$ & & $n$ & $\%$ & \\
\hline \multirow[t]{2}{*}{ Child gender } & Boy & 868 & 51.2 & & & & & & \\
\hline & Girl & 826 & 48.8 & & & & & & \\
\hline \multirow[t]{3}{*}{ Questionnaire completer } & Mother & & & 1652 & 97.5 & & 1619 & 95.6 & \\
\hline & Father & & & 38 & 2.2 & & 40 & 2.4 & \\
\hline & Unknown/other/NA & & & 4 & 0.3 & & 35 & 2.1 & \\
\hline \multirow[t]{3}{*}{ Partner questionnaire completer } & Mother & & & 33 & 1.9 & & 39 & 2.3 & \\
\hline & Father & & & 1492 & 88.1 & & 1436 & 84.8 & \\
\hline & Unknown/other/NA & & & 169 & 9.9 & & 219 & 12.9 & \\
\hline \multicolumn{2}{|l|}{ Working hours questionnaire completer } & & & & & $21.25(9.25)$ & & & \\
\hline \multicolumn{2}{|c|}{ Working hours partner questionnaire completer } & & & & & $36.71(12.84)$ & & & \\
\hline Education level (highest in household) & $\begin{array}{l}\text { Low } \\
\text { Medium } \\
\text { High }\end{array}$ & & & $\begin{array}{l}72 \\
472 \\
1145\end{array}$ & $\begin{array}{l}4.3 \\
27.9 \\
67.8\end{array}$ & & & & \\
\hline \multirow[t]{2}{*}{ Birth country female caregiver } & Netherlands & & & 1634 & 96.9 & & & & \\
\hline & Other & & & 52 & 3.1 & & & & \\
\hline \multirow[t]{2}{*}{ Birth country male caregiver } & Netherlands & & & 1622 & 96.3 & & & & \\
\hline & Other & & & 62 & 3.7 & & & & \\
\hline Recruitment channel & Conventional Alternative & $\begin{array}{l}1372 \\
322\end{array}$ & $\begin{array}{l}81.0 \\
19.0\end{array}$ & & & & & & \\
\hline \multicolumn{2}{|l|}{ Total physical activity (minutes per week) } & & & 1676 & & $610.81(394.25)$ & 1623 & & $904.48(375.42)$ \\
\hline \multicolumn{2}{|c|}{ Active transport to school (minutes per week) } & & & 1679 & & $45.10(53.11)$ & 1659 & & $108.99(106.12)$ \\
\hline \multicolumn{2}{|l|}{ Sports (minutes per week) } & & & 1694 & & $42.94(50.82)$ & 1655 & & $127.62(110.23)$ \\
\hline \multicolumn{2}{|l|}{ Playing outside (minutes per week) } & & & 1677 & & $522.42(385.30)$ & 1661 & & $669.08(319.46)$ \\
\hline \multicolumn{2}{|c|}{ Total sedentary screen-based behavior (minutes per week) } & & & 1679 & & 363.16 (292.19) & 1659 & & $553.08(351.69)$ \\
\hline \multicolumn{2}{|l|}{ Television watching (minutes per week) } & & & 1679 & & $315.71(258.45)$ & 1671 & & $417.06(263.44)$ \\
\hline \multicolumn{2}{|l|}{ Computer playing (minutes per week) } & & & 1681 & & $47.39(91.23)$ & 1665 & & $137.26(163.50)$ \\
\hline \multicolumn{2}{|l|}{ Body Mass Index z-scores } & & & 1585 & & $-0.26(0.99)$ & 1446 & & $-0.32(0.91)$ \\
\hline \multirow[t]{4}{*}{ Weight categories } & Underweight & & & 132 & 8.3 & & 102 & 7.1 & \\
\hline & Normal-weight & & & 1312 & 82.8 & & 1251 & 86.5 & \\
\hline & Overweight & & & 97 & 6.1 & & 67 & 4.6 & \\
\hline & Obesity & & & 44 & 2.8 & & 26 & 1.8 & \\
\hline
\end{tabular}

Missings educational level 5, missings BMI (5 years) 109, missings BMI (7 years) 248, missings physical activity (5 years) 18, missing physical activity (7 years) 71 , missing sedentary screen-based behavior (5 years) 15 , missings sedentary screen-based behavior (7 years) 35 , missings birth country female caregiver 8 , missings birth country male caregiver 10

and activity-related parenting practices development up to age 7 we refer to Fig. 1b. For child BMI zscore (Table 4), significant associations were only found with the parenting practice 'restriction of sedentary behavior': this association was positive in the unadjusted model (model 1) and the model adjusted for covariates (model 2). The child's physical activity was significantly related to all three activity-related parenting practices: positive for 'stimulation to be active' and 'monitoring activity', and negative for 'restriction of sedentary behavior'. The association between physical activity and restriction of sedentary behavior at age 7 attenuated after adjustment for restriction of sedentary behavior at age 5, indicating that physical activity did not influence change of this parenting practice between age 5 and 7 . The child's sedentary screen-based behavior only had a significant association with stimulation to be active. Parents of children that were sedentary at age 5 were less likely to stimulate their child to be physically active at age 


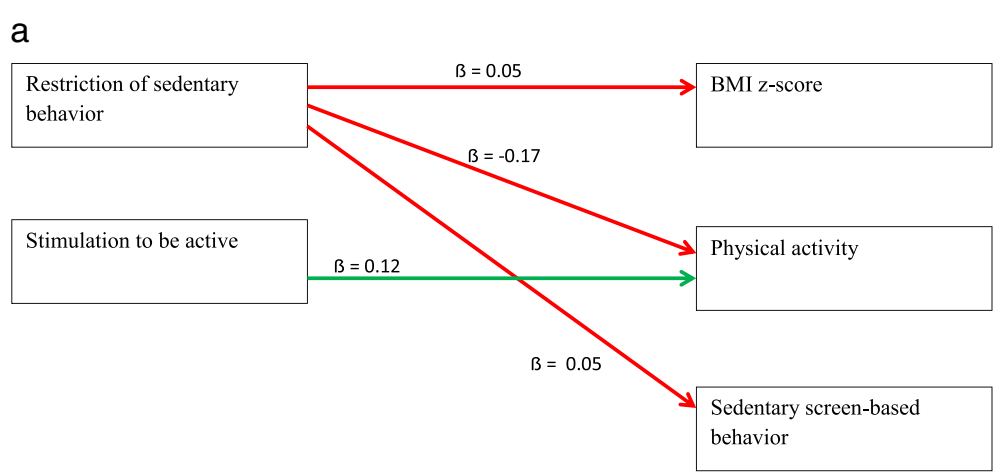

b

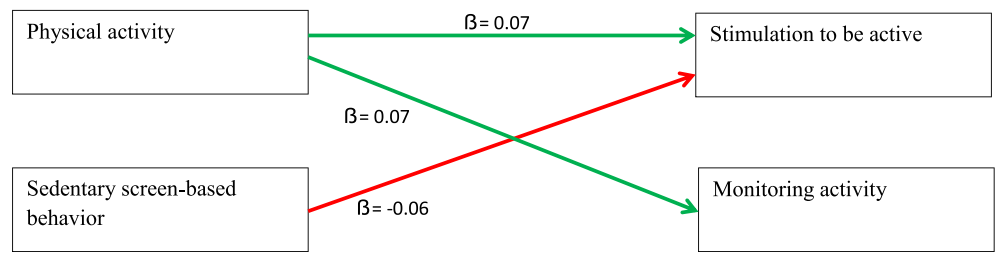

Fig. 1 a A visual representation of the significant associations between activity-related parenting practices at age 5 and child's BMI, physical activity and sedentary screen-based behavior development up to age 7. Legend: The direction of the standardized regression coefficient is presented in the figure, only for the third model (adjusted for covariates 'recruitment group (conventional vs alternative), child gender and birth weight, parental educational level, employment and country of birth' and in addition for BMI z-score at age 5 in parenting practice-BMI associations, and for either physical activity sedentary screen-based behavior in the parenting practice-physical activity/sedentary screen-based behavior associations; red line: unintended effects, green line: intended effects. $\mathbf{b}$ A visual representation of the significant associations between physical activity-related variables at age 5 and activity-related parenting practices development up to age 7. Legend: The direction of the standardized regression coefficient is presented in the figure, only for the third model (adjusted for covariates 'recruitment group (conventional vs alternative), child gender and birth weight, parental educational level, employment and country of birth' and in addition for restriction of sedentary screen-based behavior at age 5 in the activity-related variables \& BMI-restriction of sedentary screen-based behavior association, and for either stimulation to be active or monitoring activity in the activity-related variables \& BMI- stimulation to be active or monitoring activity parenting practice associations; Green line: reinforcing effect, red line: reactance effect

7. This association remained significant after correcting for potential confounders and considering the parenting practice 'stimulation to be active' at age 5 .

\section{Discussion}

This study examined the bidirectional associations between activity-related parenting practices (i.e., restriction of sedentary behavior, stimulation to be active, and monitoring activity) and the child's BMI, physical activity levels, and sedentary screen-based behavior. To date, the focus in the literature has very much been on activityrelated parenting practices as a risk factor for low levels of physical activity and high levels of sedentariness among children or high body weight. Our study reveals that children influence parenting as much as the other way around behavior.

In this study we found that child sedentary screenbased behavior negatively influenced stimulation of physical activity. In cross-sectional studies such a finding could easily be misinterpreted as parental stimulation to be active having a detrimental impact on children's sedentary screen-based behavior, for example when they push children too much. However, our results suggest the reverse is true. It thus seems that parents of children with high levels of sedentary screen-based behavior do not stimulate their children (anymore) to be physically active. Parents might reach a point where unsuccessful efforts te decrease their child's sedentary time in the past, have led to decreased self-efficacy to address the child's behavior, which in turn influences their parenting practices [21]. Alternatively, parents might not consider sedentarity as a problem, or perceive it as an unchangeable trait of the child.

Parents are additionally responding to child physical activity levels; parents were more likely to monitor their child's activity when the child was already physically active. These parents are probably enthusiastic about their child's willingness to be physically active and therefore supporting and motivating their child, which could be characterized by increased monitoring of their child's activity behavior.

In addition, we found that stimulation of physical activity led to higher levels of physical activity, but also that physical activity was positively related to stimulation of physical activity. This process can be characterized as a reinforcing or positive feedback loop. A feedback loop 
Table 3 Association between activity-related parenting practices at age 5 and child's BMl, physical activity and sedentary screenbased behavior development up to age 7

\begin{tabular}{lllll}
\hline & \multicolumn{4}{l}{$\begin{array}{l}\text { Standardized regression coefficients } \\
(\beta)\end{array}$} \\
\cline { 3 - 5 } $\begin{array}{l}\text { Activity-related } \\
\text { parenting practices }\end{array}$ & Model & $\begin{array}{l}\text { BMl z- } \\
\text { score }\end{array}$ & $\begin{array}{l}\text { Physical } \\
\text { activity }\end{array}$ & $\begin{array}{l}\text { Sedentary screen- } \\
\text { based behavior }\end{array}$ \\
\hline Restriction of sedentary & 1 & $0.13^{* * *}$ & $-0.25^{* * *}$ & $0.07^{*}$ \\
behavior & 2 & $0.13^{* * *}$ & $-0.23^{* * *}$ & $0.08^{* *}$ \\
& 3 & $0.05^{*}$ & $-0.17^{* * *}$ & $0.05^{\mathrm{a}}$ \\
Stimulation to be active & 1 & -0.02 & $0.16^{* * *}$ & 0.00 \\
& 2 & -0.02 & $0.15^{* * *}$ & -0.03 \\
& 3 & -0.02 & $0.12^{* * *}$ & 0.01 \\
Monitoring activity & 1 & -0.04 & -0.01 & -0.05 \\
& 2 & -0.04 & -0.02 & -0.03 \\
& 3 & 0.00 & -0.03 & 0.00 \\
\hline
\end{tabular}

${ }^{*} p<0.05,{ }^{* *} p<0.01,{ }^{* * *} p<0.001$; a the $p$-value was marginally significant: $p=0.055$; model 1 : unadjusted; model 2 : adjusted for recruitment group (conventional vs alternative), child gender and birth weight, parental educational level, employment and country of birth; model 3: adjusted for covariates from model 2 and in addition for BMl z-score at age 5 in parenting practice-BMI associations, and for either physical activity or sedentary screen-based behavior at age 5 in the parenting practice-physical activity/sedentary behavior associations; Explained variances (R2): for BMl: Model $1=0.01$, Model $2=0.06$, Model $3=0.39$; for Physicalactivity: Model $1=0.08$, Model $2=0.13$, Model $3=0.21$; for Sedentary screen-based behavior: Model $1=0.01$, Model $2=0.13$, Model $3=0.38$

Table 4 Association between physical activity-related variables at age 5 and activity-related parenting practices development up to age 7

\begin{tabular}{|c|c|c|c|c|}
\hline \multirow{2}{*}{$\begin{array}{l}\text { Physical activity related } \\
\text { variables }\end{array}$} & \multirow[b]{2}{*}{ Model } & \multicolumn{3}{|c|}{ Standardized regression coefficients ( $\beta$ ) } \\
\hline & & $\begin{array}{l}\text { Restriction of } \\
\text { sedentary } \\
\text { behavior }\end{array}$ & $\begin{array}{l}\text { Stimulation } \\
\text { to be active }\end{array}$ & $\begin{array}{l}\text { Monitoring } \\
\text { activity }\end{array}$ \\
\hline \multirow[t]{3}{*}{ BMI z-score } & 1 & $0.08^{* *}$ & 0.04 & 0.02 \\
\hline & 2 & $0.08^{* *}$ & 0.04 & 0.02 \\
\hline & 3 & 0.03 & 0.03 & 0.02 \\
\hline \multirow[t]{3}{*}{ Physical activity } & 1 & $-0.11^{* * *}$ & $0.11^{* * *}$ & $0.07^{*}$ \\
\hline & 2 & $-0.12^{* * *}$ & $0.11^{* * *}$ & $0.07^{*}$ \\
\hline & 3 & -0.03 & $0.07^{* *}$ & $0.07^{*}$ \\
\hline \multirow{3}{*}{$\begin{array}{l}\text { Sedentary screen- } \\
\text { based behavior }\end{array}$} & 1 & 0.00 & $-0.07^{* *}$ & -0.05 \\
\hline & 2 & 0.02 & $-0.09^{* *}$ & -0.04 \\
\hline & 3 & 0.00 & $-0.06^{*}$ & -0.03 \\
\hline
\end{tabular}

${ }^{*} p<0.05,{ }^{* *} p<0.01,{ }^{* * *} p<0.001$; model 1: unadjusted; model 2: adjusted for recruitment group (conventional vs alternative), child gender and birth weight, parental educational level, employment and country of birth; model 3: adjusted for covariates from model 2 and in addition for restriction of sedentary behavior at age 5 in the activity-related variables \& BMl-restriction of sedentary behavior association, and for either stimulation to be active or monitoring activity in the activity-related variables \& BMl-stimulation to be active or monitoring activity parenting practice associations. Explained variances $\left(\mathrm{R}^{2}\right)$ : for Restriction of sedentary behavior: Model $1=0.02$, Model $2=0.06$, Model $3=0.31$; for Stimulation to be active: Model $1=0.02$, Model $2=0.04$, Model $3=0.20$; for Monitoring activity: Model $1=0.01$, Model $2=0.01$, Model $3=0.16$ is a path along which information can be traced from one point in a system, and back to the point of origin. Feedback loops are an essential feature of system dynamics modeling [22]. In the current study, we found strong indications for the existence of such positive feedback loops. This is notable, since traditional health behavior theories often assume homeostasis or negative feedback loops: low levels of child PA would lead to parental stimulation, which would lead to more PA. The existence of positive feedback loops like those uncovered in the current study, may particularly explain nonlinearity of environment - behavior relationships in the area of childhood obesity [23]. It may accurately describe the process where parents and children unintentionally become caught into a negative spiral from which it is hard to escape (i.e. more sedentary behavior leading to less stimulation to be active, in turn leading to even more sedentary behavior, and so on). However, the findings with regard to stimulation of physical activity and actual physical need to be interpreted with caution, as both concepts have a slightly different focus as regards the type of physical activity (i.e. focus on active travel versus on physical activity in general, respectively).

Restriction of sedentary behavior was found to have a detrimental impact on child activity-related and BMI outcomes; it was associated with an increase of child BMI and a decrease in child physical activity behavior. In accordance with the literature about restriction in the feeding domain, where food restriction could lead to an increase of children's desire and intake of forbidden foods [24], it could be that children who are restricted in the amount of screen time increase their preferences for these behaviors and act upon that by being less physically active. However, we did not find that parents adapted their restrictive parenting practices to deviations in child outcomes (i.e. BMI z-score, physical activity, and sedentary screen-based behavior). It thus seems that parents do not (further) restrict their child's sedentary behavior when their child is overweight or less active.

\section{Study strengths and limitations}

This study is unique in its study design. Data were prospectively collected in a large cohort, and activity-related parenting practices and child physical activity-related variables were measured similarly on two time points. Although the questionnaires that were used were previously validated [13, 15], they have been used in only a few studies. We recommend replication studies using other parenting questionnaires, investigating the bidirectionality of the association between child outcomes and other parenting practices (such as parental modeling of activities). Also as regards behavior other questionnaires, including measures of other behaviours, might be worthwhile, as our study was limited to screen-based sedentary activities. Other 
sedentary behaviors such as reading are an understudied topic. Parental efforts decrease sedentary time might merely cause shifts from one type of sedentary behavior to another. Our study is further limited as it relies on self-reports. This systematic bias may produce spurious results. For instance, parents are likely to underestimate their children's weight and overestimate height, especially if their child was overweight or obese, whereas parents of underweight children tended to overestimate weight [25]. This could be a reason why our study reported lower percentages of overweight/ obesity $(8.9 \%$ at age 5 and $6.4 \%$ at age 7$)$ compared to the Dutch reference population of children aged 5-7 (2009: ranging from $12.8 \%$ and $18.8 \%$ for overweight and from $2.0 \%$ to $3.4 \%$ for obesity) [26]. It is likely that the present study yielded underestimates of associations between the activity-related parenting practice scales and child physical activity-related and BMI variables and vice versa, because of the parental reported nature of this study. This dilution of effects could also be due to imprecision of measurements and possible misspecification of models through assumptions of linearity. Future efforts should address more measurement points. While mutual influence between parent and child is a repeated, continuous process of interactions and adaptations, this process may likely be non-linear. Future studies could also establish whether the time lag of activity-related parenting practices that influence child physical activity-related variables is similar or different from the time lag for child physical activity-related variables to influence activity-related parenting practices.

\section{Conclusions}

This study addresses the importance of conducting longitudinal research to get insight into the bidirectional nature of parent-child relations with regard to activity-related behavior. Parents and children are continuously adapting to each other and future efforts should make further progress in this area by addressing system dynamics in the home setting. The mutual influence between parents and children in influencing their activity-related behaviors could lead parents to unintentionally and unconsciously become caught into a negative spiral from which it is hard to escape (i.e., reinforcing causal loop chains). It is important to give those parents support as regards raising awareness for such processes and parenting practices that they could apply to get their child to become more physically active.

\section{Abbreviations}

BMI: Body Mass Index; CITC: Corrected Item-Total Correlations; PA: Physical activity

Acknowledgements

Not applicable.

\section{Funding}

This work was supported by the Netherlands Heart Foundation (E.F.C.S., grant number 2014 T037); and the Netherlands Organization for Scientific Research (NWO), Division for the Social Sciences (MaGW), the Netherlands (J.S.G., grant number 016.145.091). Financial support for the follow-up of the KOALA Birth Cohort Study at age 5 was provided by the Dutch Ministry of Economic Affairs, the Dutch Ministry of Health, Welfare and Sports, FrieslandCampina and the Dutch Sugar Bureau, all in the Netherlands.

\section{Availability of data and materials}

The datasets used and/or analyzed during the current study available from the corresponding author on reasonable request.

\section{Authors' contributions}

ES and JG conceptualized the study. ES, JG and CT were involved in data collection, ES conducted the statistical analyses, interpreted the data, and drafted the manuscript. All authors reviewed draft versions of the manuscript and provided feedback. JG revised the manuscript after peer review. All authors read and approved the final manuscript.

\section{Ethics approval and consent to participate}

Informed consent was signed by all parents, and ethical approval was obtained from the Maastricht University/University Hospital Maastricht medical ethics committee.

\section{Consent for publication}

Not applicable.

\section{Competing interests}

The authors declare that they have no competing interests.

\section{Author details}

${ }^{1}$ Department of Health Promotion, NUTRIM School of Nutrition and Translational Research in Metabolism, Maastricht University, Maastricht University Medical Center, P.O. Box 616, 6200 MD Maastricht, the Netherlands. ${ }^{2}$ Department of Epidemiology, Maastricht University, CAPHRI Care and Public Health Research Institute, P.O. Box 616, 6200 MD Maastricht, the Netherlands.

Received: 16 March 2017 Accepted: 29 June 2017

Published online: 06 July 2017

References

1. Darling N, Steinberg L. Parenting style as a context: an integrative model. Psychol Bull. 1993;113:487-98.

2. Vaughn AE, Tabak RG, Bryant MJ, Ward DS. Measuring parent food practices: a systematic review of existing measures and examination. Int J Behav Nutr Phys Act. 2013;10:61

3. $\mathrm{Xu} \mathrm{H}$, Wen LM, Rissel C. Associations of parental influences with physical activity and screen time among young children: a systematic review. J Obes. 2015;2015: 546925.

4. Jago R, Edwards MJ, Urbanski CR, Sebire SJ. General and specific approaches to media parenting: a systematic review of current measures, associations with screen-viewing, and measurement implications. Child Obes. 2013;9:551-72.

5. Sleddens EFC, Kremers SPJ, Hughes SO, Cross MB, Thijs C, De Vries NK, et al. Physical activity parenting: a systematic review of questionnaires and their associations with child activity levels. Obes Rev. 2012;13:1015-33.

6. Afonso L, Lopes C, Severo M, Santos S, Real H, Durão C, et al. Bidirectional associations between parental child-feeding practices and body mass index at 4 and 7 y of age. Am J Clin Nutr. 2016;103:861-7.

7. Jansen PW, Tharner A, van der Ende J, Wake M, Raat H, Hofman A, et al. Feeding practices and child weight: is the association bidirectional in preschool children? Am J Clin Nutr. 2014;100:1329-36.

8. Rhee KE, Coleman SM, Appugliese DP, Kaciroti NA, Corwyn RF, Davidson NS, et al. Maternal feeding practices become more controlling after and not before excessive rates of weight gain. Obesity (Silver Spring). 2009;17:1724-9.

9. Webber L, Cooke L, Hill C, Wardle J. Child adiposity and maternal feeding practices: a longitudinal analysis. Am J Clin Nutr. 2010;92:1423-8.

10. Berge JM. A review of familial correlates of child and adolescent obesity: what has the 21st century taught us so far? J Adolesc Med Health. 2009;21:457-83. 
11. Patrick H, Hennessy E, McSpadden K, Oh A. Parenting styles and practices in children's obesogenic behaviors: scientific gaps and future research directions. Child Obes. 2013;9:S73-86.

12. Kummeling I, Thijs C, Penders J, Snijders BE, Stelma F, Reimerink J, et al. Etiology of atopy in infancy: the KOALA birth cohort study. Pediatr Allergy Immunol. 2005; 16:679-84.

13. Gubbels JS, Kremers SPJ, Stafleu A, De Vries SI, Goldbohm RA, Dagnelie PC Association between parenting practices and children's dietary intake, activity behavior and development of body mass index: the KOALA birth cohort study. Int J Behav Nutr Phys Act. 2011;8:18.

14. Birch LL, Fisher JO, Grimm-Thomas K, Markey CN. Confirmatory factor analysis of the child feeding questionnaire: a measure of parental attitudes, beliefs and practices about child feeding and obesity proneness. Appetite. 2001;36:201-10.

15. Monitor Jeugdgezondheid: Standaard Vraagstelling Bewegen (Standard Questionnaire Physical Activity). GGD Nederland, Rijksinstituut voor Volksgezondheid en Milieu (RIVM) and Actiz organisatie van zorgondernemers; 2009.

16. Fredriks AM, van Buuren S, Wit JM, Verloove-Vanhorick SP. Body index measurements in 1996-1997 compared with 1980. Arch Dis Child. 2000;82:107-12.

17. Barlow SE. Expert committee recommendations regarding the prevention, assessment, and treatment of child and adolescent overweight and obesity: summary report. Pediatrics. 2007;120(S4):S164-S92. Aappublications. org/ content/120/Supplement_4

18. Eurostat. Task force on Core social variables. Final report. Luxembourg: European Communitees; 2007.

19. Portney $L G$, Watkins MP. Foundations of clinical research: applications to practice. 2nd ed. Upper Saddle River, NJ: Prentice Halli;2000.

20. Bernstein IH, Nunnally J. Psychometric theory. New York: McGraw-Hill; 1994.

21. Gerards SMPL, Hummel K, Dagnelie PC, De Vries NK, Kremers SPJ. Parental self-efficacy in childhood overweight: validation of the lifestyle behavior checklist in the Netherlands. Int J Behav Nutr Phys Act. 2013;10:7.

22. Sterman JD. Business dynamics: systems thinking and modeling for a complex world. New York: Irwin/McGraw-Hill; 2000.

23. Hamid TKA. Thinking in circles about obesity: applying systems thinking to weight management. New York: Springer; 2009.

24. Jansen E, Mulkens S, Jansen A. Do not eat the red food!: prohibition of snacks leads to their relatively higher consumption in children. Appetite. 2007;49:572-7. doi:10.1016/j.appet.2007.03.229

25. Scholtens S, Brunekreef B, Visscher TLS, Smit HA, Kerkhof M, De Jongste JC, Gerritsen J, Wijga AH. Reported versus measured body weight and height of 4-year-old children and the prevalence of overweight. Eur J Pub Health. 2007;17:369-74

26. Schönbeck Y, Talma H, van Dommelen P, Bakker B, Buitendijk SE, Hirasing $R A$, van Buuren S. Increase in prevalence of overweight in Dutch children and adolescents: a comparison of nationwide growth studies in 1980, 1997 and 2009. Plos One. 2011;6:e27608. doi:10.1371/journal.pone.0027608.

\section{Submit your next manuscript to BioMed Central and we will help you at every step:}

- We accept pre-submission inquiries

- Our selector tool helps you to find the most relevant journal

- We provide round the clock customer support

- Convenient online submission

- Thorough peer review

- Inclusion in PubMed and all major indexing services

- Maximum visibility for your research

Submit your manuscript at www.biomedcentral.com/submit

CBiomed Central 